\title{
Current Situation and Perspectives on Hantaviruses in Mexico
}

\author{
Ana L. Vigueras-Galván ${ }^{1}$, Andrés M. López-Pérez ${ }^{1}$, Gabriel E. García-Peña ${ }^{1}$, \\ Oscar Rico-Chávez ${ }^{1}$, Rosa E. Sarmiento-Silva ${ }^{2}$ and Gerardo Suzán ${ }^{1, *}$ \\ 1 Laboratorio de Ecología de Enfermedades y Una Salud, Departamento de Etología, Fauna Silvestre y \\ Animales de Laboratorio, Facultad de Medicina Veterinaria y Zootecnia, Universidad Nacional Autónoma \\ de México, Av. Universidad 3000, UNAM-CU, Coyoacán and CDMX CP 04510, Mexico \\ 2 Laboratorio de Virología, Departamento de Microbiología e Inmunología, Facultad de Medicina Veterinaria \\ y Zootecnia, Universidad Nacional Autónoma de México. Av. Universidad 3000, UNAM-CU, Coyoacán, \\ CDMX. CP 04510, Mexico \\ * Correspondence: gerardosuz@gmail.com; Tel.: +52-555-622-5941
}

Received: 17 May 2019; Accepted: 9 July 2019; Published: 12 July 2019

\begin{abstract}
Hantaviruses are transmitted by rodents producing the hantavirus pulmonary syndrome (HPS) in the Americas. Today, no human cases of HPS have been reported in Mexico in spite of similar environmental conditions with Central America and the USA where several cases have occurred. To understand the current situation of hantaviruses in Mexico and the public health risk, a systematic review of studies was conducted reporting hantaviruses in rodents to known state seroprevalence and hantavirus genotypes. Simultaneously, this study identified the potential hantaviruses based on the phylogenetic diversity (PD) of hantaviruses reported in the Americas in hosts with the distribution in Mexico. A total 3862 rodents belonging to 82 species have been tested since 1999 to 2017. Overall, 392 individuals representing 43 rodent species were seropositive, and the seroprevalence ranged from 0 to $69.22 \%$. Seven hantaviruses genotypes have been described in Mexico and three are zoonotic. Four host species of rodents are widely distributed in Mexico harboring the highest PD of viruses. According to the hosts distribution, 16 genotypes could be circulating in Mexico and some of these represent a potential risk for public health. This study proposed multidisciplinary and interinstitutional collaborations to implement systematic surveillance in rodents.
\end{abstract}

Keywords: hantavirus; Mexico; neglected disease; rodents; zoonoses

\section{Introduction}

Hantaviruses are RNA viruses of the genus Orthohantavirus, which are transmitted by rodents of the family Muridae. They cause hemorrhagic fever with renal syndrome (HFRS) and hantavirus pulmonary syndrome (HPS). These diseases are mainly associated with rural areas, as infection in humans occurs following the inhalation of aerosolized feces, urine, and saliva of infected rodents. Hemorrhagic fever with renal syndrome is reported in Europe and Asia and affects up to 30,000 people a year with a mortality rate of 0.1 to $15 \%$ [1]. Hantavirus pulmonary syndrome is endemic to the Americas and was first reported in 1993 in the four corners region in southwestern United States. When the first outbreaks started, $60 \%$ of infected people died and today, mortality decreased to $36 \%$. In the United States, 731 cases were reported from 1993 to 2018, 40\% of which were reported in the states along the United States-Mexico border [2-4]. Hantavirus pulmonary syndrome also occurs in different countries from Central America, such as Panama, where 259 human cases were reported from 1999 to 2016, with a mortality rate of 17\% [5]. During 2018, a total of 103 confirmed cases of hantavirus have been reported in Panama. Further, 51 cases were classified as hantavirus fever without pulmonary syndrome and 48 cases were classified as HPS [6]. 
No human cases of HPS in Mexico have been reported to date in spite of several outbreaks of HPS reported in the USA southern border, and the constant reports of rodents harboring hantavirus antibodies along the northern border of Mexico. This disease is likely to occur in Mexico and probably has been misidentified due to the fact that signs and symptoms are similar to other prevalent diseases, such as dengue, leptospirosis, rickettsiosis, and influenza [7].

Reservoirs of hantaviruses responsible for HFRS in Europe and Asia are rodents of the family Muridae (subfamily Murinae) [8], while the reservoirs of HPS in the Americas are of the family Cricetidae (subfamilies Arvicolinae, Neotominae and Sigmodontinae) [9]. Hantaviruses have been occasionally reported in other rodent families, such as Heteromyidae and Echimyidae, as well as in bats, marsupials, and soricomorphs, but their potential as competent reservoirs is still unknown [10-12]. Thus far, more than 40 hantaviruses genotypes in the Americas have been reported in the scientific literature, of which at least 20 genotypes were considered zoonotic [13].

Mexico has similar environmental conditions with Central America (neotropical region), and with the southern states of the USA where several human cases of HPS have been reported. In addition, there are more than 120 species of cricetids in Mexico, which means a potentially large diversity of hosts and hantaviruses [14]. Based on this, the authors hypothesized that a great diversity of unknown hantaviruses were likely to occur all over the country. The objective of our study is to explore the situation in Mexico with regard to hantaviruses. To do this, the published reports of hantaviruses in Mexico were analyzed and the geographic distribution of the seroprevalence in wildlife hosts in the different states allover Mexico was examined. Based on an analysis of genomic sequences reported in GenBank, the genetic diversity of hantaviruses in all known reservoirs from the Americas was estimated to identify the rodent species currently present in Mexico that harbor the greatest genetic diversity of hantaviruses. With this information, the authors produced a map of the potential distribution of hantavirus reservoirs. In light of our results, guidelines and priorities for disease prevention and future research are suggested from both an ecological and public health perspectives.

\section{Methods}

The authors searched for reports in the ScienceDirect, Scopus and Web of Science databases using the search criteria (Hantavirus; Mexico; rodent host) and (Hantavirus; Mexico). In order to increase the number of national reports, the scientific literature in the TESIUNAM and INDIXIE databases of the Red Mexicana de Repositorios Institucionales (Mexican Network of Institutional Repositories) were searched, with the search criterion (Hantavirus). The authors found 27 documents published during the period from 1995 to 2017, and of these, 15 studies were used to identify the regional seroprevalence (Table S1). The studies that did not identify species, geographic location or the number of individuals analyzed, as well as duplicate data, were excluded. One study reporting hantavirus antibodies in humans was also included, and unpublished data from three projects from the Laboratorio de Ecología de Enfermedades y Una Salud (Laboratory of Disease Ecology and One Health) of the FMVZ-UNAM. The studies were done in Hidalgo, Sonora and Mexico City [15-17].

In total, rodent studies were carried out in 65 localities distributed in 24 Mexican states out of 32. This study recorded a total of 82 rodent species analyzed belonging to four families: Cricetidae (65), Heteromyidae (14), Muridae (2) and Sciuridae (1).

Fourteen studies used enzyme-linked immunosorbent assay (ELISA) and one used immunofluorescence. The antigens used were Sin Nombre Virus (SNV), Caño Delgadito othohantavirus (CDV) and Montano Orthohantavirus (MTNV). Seroprevalence (SP) of hantavirus in rodents of Mexico was calculated as the number of individuals with hantavirus antibodies $\left(N_{i p}\right)$ divided by the total number of individuals analyzed $\left(N_{i}\right)$. The number of individuals analyzed by each species (Sp) varied from 1 to 414 and by State from 5 to 889 . Thus, to reduce the variation in the estimates of seroprevalence due to the differences in the number of individuals analyzed by State and species, the seroprevalence 
was weighted $\left(\mathrm{SP}_{\mathrm{w}}\right)$ by the number of individuals analyzed $\left(\mathrm{N}_{\mathrm{i}}\right) \log 10$ transformed $[18,19]$. In this way, the overrepresentation of species and States with a large sample size was avoided.

$$
S P w=\log 10(N i) \times S P
$$

To assess the genetic diversity of hantavirus circulating within each species, the authors calculated the phylogenetic diversity (PD) of 60 sequences from the $S$ segment of the genome (encode the nucleocapsid protein, N) of hantaviruses reported in 41 reservoir species in America. Firstly, with the sequences, a phylogenetic tree using the neighbor-joining method by the Kimura two-parameter distance method was constructed. Secondly, the PD based on the phylogenetic tree was calculated by adding up the total branch length of the sequences analyzed per host species [20]. In this way, the host species that harbor the most diverse hantaviruses based on PD was identified.

The authors then determined whether or not these species were distributed in Mexico to establish the possible geographic distribution of reservoirs and orthohantaviruses in the country. To do this, maps were built of geographical distribution of the reservoir species currently present in Mexico that harbor the greatest genetic diversity of orthhantaviruses. The distribution layers available in the Geographic Metadata Catalog of the Comisión Nacional para el Conocimiento y uso de la Biodiversidad [21-24] and QGIS Geographical Information System were used.

\section{Results}

Rodent studies were carried out in 65 localities distributed in 24 Mexican states from 32. This study recorded a total of 82 rodent species analyzed belonging to four families: Cricetidae (65), Heteromyidae (14), Muridae (2) and Sciuridae (1). Fourteen studies used enzyme-linked immunosorbent assay (ELISA) and one used immunofluorescence. The antigens used were SNV, Caño Delgadito virus (CDV) and Montano virus (MTNV). The overall seroprevalence of hantavirus in rodents was $10.15 \%$ (392/3862). Rodent and Orthohantavirus surveillance have been conducted in 75\% (24/32) of the Mexican states, of which 18 have reported antibodies against Orthohantavirus in rodents. Seroprevalence ranges from 0 to $69.22 \%$ among different regions of the country (Figure 1, Table S2). Hidalgo (69.22\%) had the highest seroprevalence, followed by Chihuahua $(49.02 \%)$. The studies carried out in humans report a seroprevalence that ranged from 1.4 to $1.6 \%$ in the states of Colima, Hidalgo, Guanajuato, Mexico City, and Chihuahua [25].

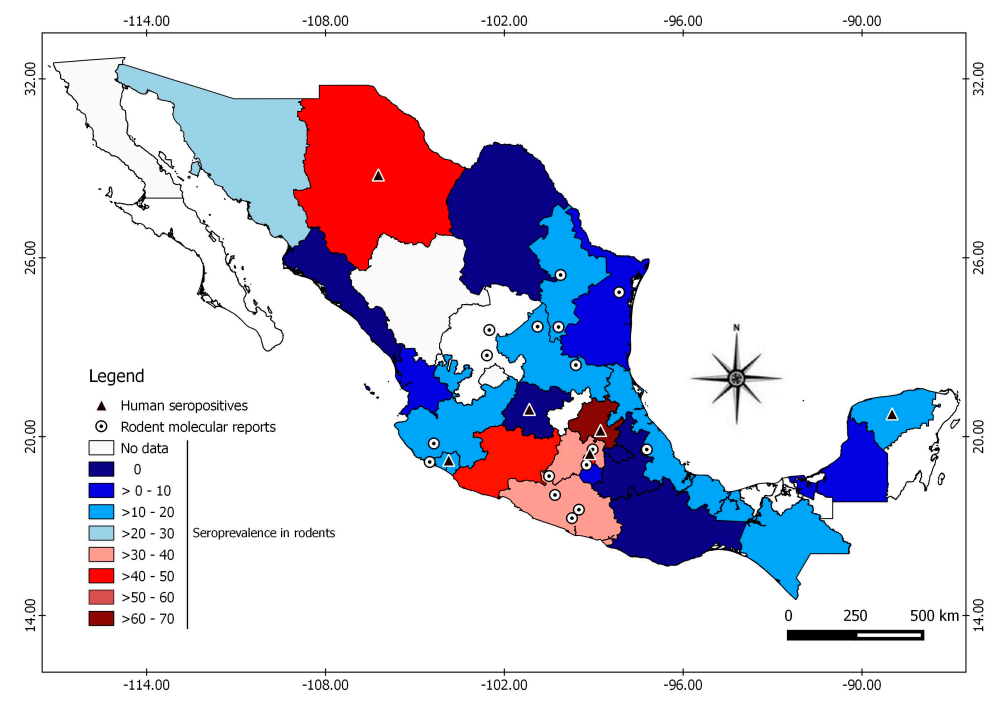

Figure 1. Geographic distribution of rodent and human reports of orthohantaviruses in Mexico. The seroprevalence in rodents is shown in the colored states, the molecular evidence in rodents with circles, and the serological evidence in humans with triangles. 
Divided by rodent family, Orthohantavirus seroprevalences were $34.41 \%$ in Cricetidae, $34.01 \%$ in Heteromydae, $10.60 \%$ in Sciuridae and 10.43\% in Muridae. This study recorded 43 seropositive species among the 82 analyzed. The seroprevalence by species ranged from 3\% to 76\% (Figure 2, Table S3). Seropositive individuals were identified from the genera Peromyscus, Reithrodontomys, Sigmodon, Oryzomys and Oligoryzomys, which have species considered to be reservoirs of American orthohantaviruses. Seropositive individuals of the genera Rattus and Mus were also identified and considered reservoirs of Eurasian orthohantaviruses.

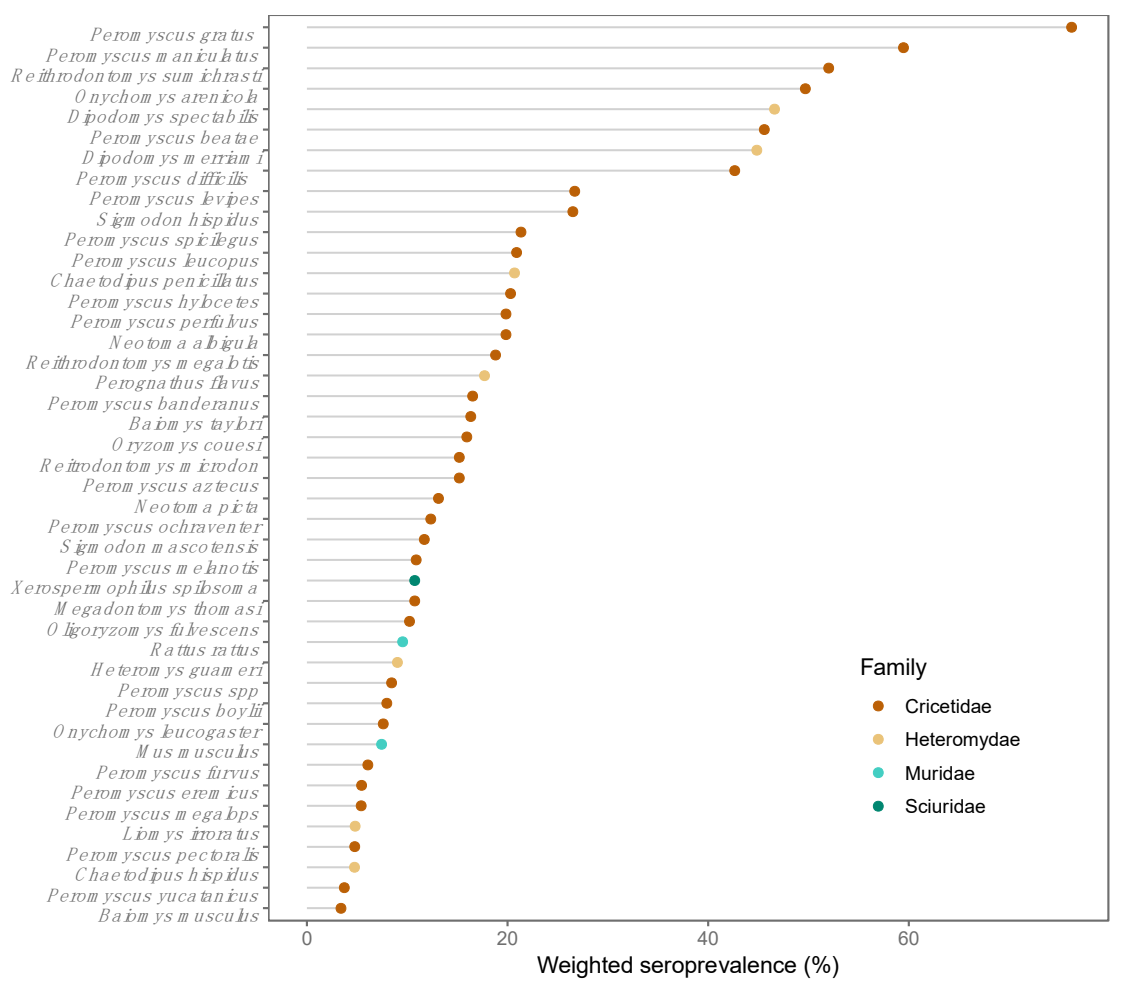

Figure 2. Seropositive species and weighted prevalence.

Thus far, seven Orthohantaviruses genotypes have been reported in 12 rodent species from ten Mexican states. These genotypes include the Montano orthohantavirus (MTNV), Huitzilac orthohantavirus (HUIV), Carrizal orthohantavirus (CARV) and Playa de Oro orthohantavirus (OROV), considered endemic to Mexico, the Limestone Canyon orthohantavirus (LSCV, not associated with illness) and two zoonotic hantaviruses, SNV and El Moro Canyon orthohantavirus (ELMC) (Table 1). In addition, given the distribution of potential rodent and soricomorphs hosts, at least 16 genotypes of hantaviruses previously reported in America could be present in Mexico (Table 2). From these 16 genotypes, at least nine are considered zoonotic, and seven have not still been associated with disease in humans. From the nine zoonotic viruses, six are from the USA and three are from Central America.

Twenty-two of the 41 species in which Orthohantavirus sequences have been reported in America are distributed in Mexico, and orthohantaviruses have been identified in Mexico in 14 of these species. According to the PD analysis, the rodent species Oryzomys couesi, Reithrodontomys megalotis, Peromyscus maniculatus, and Peromyscus leucopus harbor the highest hantaviruses PD, all of which are widely distributed in Mexico (Figures 3 and 4). 
Table 1. Genotypes of orthohantaviruses identified in Mexico by species and State.

\begin{tabular}{|c|c|c|}
\hline State & Species & Orthohantavirus Genotype \\
\hline \multirow{2}{*}{ Zacatecas } & Reithrodontomys megalotis & ELMC * \\
\hline & Reithrodontomys megalotis & $\mathrm{SNV}^{*}$ \\
\hline \multirow{2}{*}{ Colima } & Oryzomys couesi & OROV \\
\hline & Sigmodon mascotensis & OROV \\
\hline \multirow{4}{*}{ Guerrero } & Peromyscus batae & MTNV \\
\hline & Peromyscus aztecus & MTNV \\
\hline & Reithrodontomys sumichrasti & CARV \\
\hline & Peromyscus megalops & CARV \\
\hline Morelos & Reithrodontomys megalotis & HUIV \\
\hline Guerrero & Peromyscus batae & HUIV \\
\hline Guerrero & Reithrodontomys sumichrasti & ELMC * \\
\hline Jalisco & Peromyscus spicilegus & LSCV \\
\hline \multirow{2}{*}{ Mexico State } & Peromyscus melanotis & LSCV \\
\hline & Peromyscus hylocetes & LSCV \\
\hline \multirow{3}{*}{ Nuevo León } & Peromyscus maniculatus & $\mathrm{SNV}^{*}$ \\
\hline & Peromyscus eremicus & $\mathrm{SNV}^{*}$ \\
\hline & Peromyscus levipes & LSCV \\
\hline \multirow{2}{*}{ San Luis Potosí } & Peromyscus maniculatus & $\mathrm{SNV}^{*}$ \\
\hline & Peromyscus ochraventer & LSCV \\
\hline Tamaulipas & Peromyscus leucopus & SNV \\
\hline \multirow{3}{*}{ Veracruz } & Reithrodontomys megalotis & ELMC \\
\hline & Peromyscus melanotis & ELMC \\
\hline & Peromyscus maniculatus & SNV \\
\hline
\end{tabular}

*Zoonotic.

Table 2. Reservoirs present in Mexico and their orthohantaviruses genotypes.

\begin{tabular}{cccc}
\hline Reservoir & Genotypes Orthohantaviruses & Country & Disease \\
\hline Oligoryzomys fulvescens & Choclo orthohantavirus & Panama & HPS \\
Oryzomys palustris & Bayou orthohantavirus & USA & HPS \\
Sigmodon hispidus & Black Creek Canal & USA & HPS \\
Peromyscus maniculatus & Monongahela orthohantavirus & USA & HPS \\
Peromyscus leucopus & New York orthohantavirus & USA & HPS \\
Microtus pennsylvanicus & Prospect Hill orthohantavirus & USA & NR \\
Oligoryzomys fulvescens & Maporal orthohantavirus & Venezuela & NR \\
Oryzomys couesi & Catacamas orthohantavirus & Honduras & HPS \\
Oryzomys couesi & Caño delgadito orthohantavirus & Honduras & HPS \\
Sorex monticolus & Jemez Springs orthohantavirus & USA & NR \\
Scalopus aquaticus & Rockport orthohantavirus & USA & NR \\
Microtus californicus & Isla Vista orthohantavirus & USA & NR \\
Peromyscus leucopus & Blue River orthohantavirus & USA & HPS \\
Reithrodontomys & Rio Segundo orthohantavirus & Costa Rica & NR \\
mexicanus & Muleshoe orthohantavirus & USA & NR \\
Sigmodon hispidus & Convict Creek orthohantavirus & USA & HPS \\
Peromyscus maniculatus & HA &
\end{tabular}

HPS: Hantavirus Pulmonary Syndrome; NR: Not recognized. 


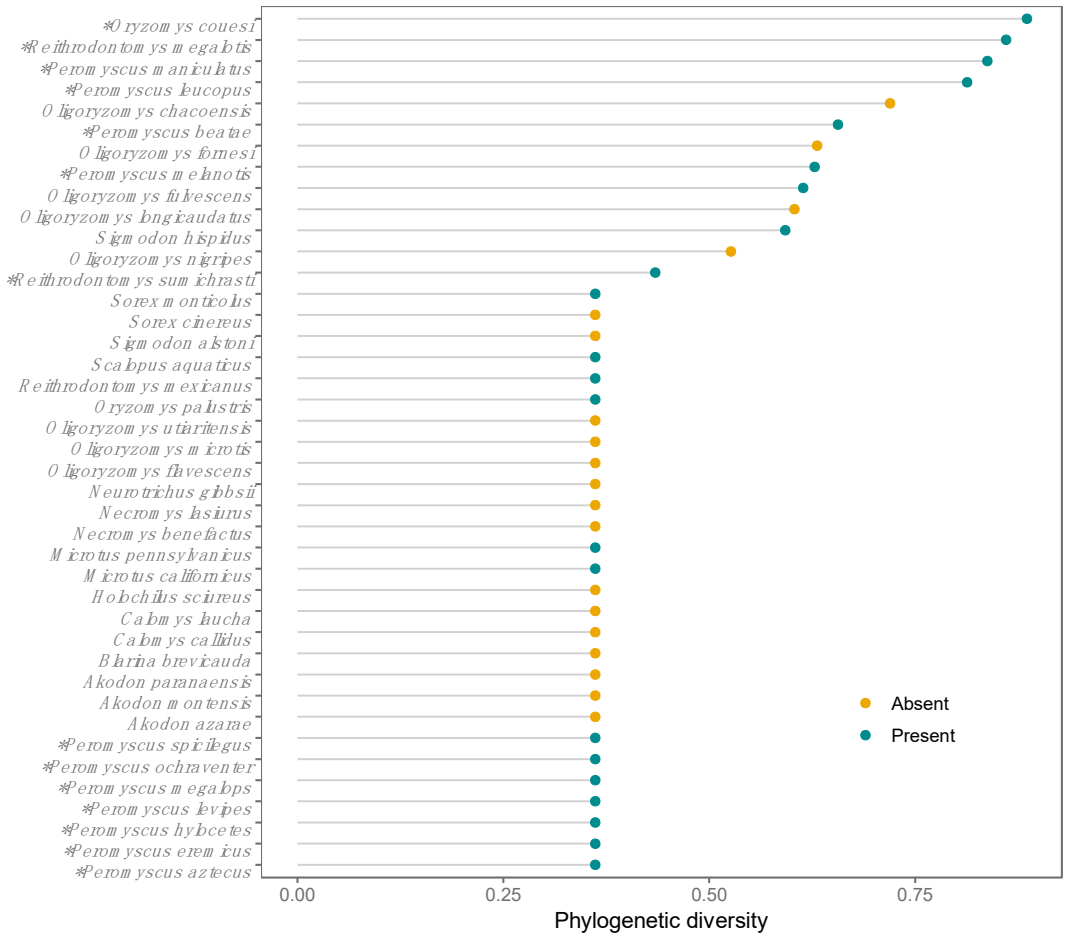

Figure 3. Phylogentic diversity of Orthohantavirus per reservoir in the Americas. Coloured points showed species absent and present in Mexico. * Species in which orthohantaviruses genotypes have been identified in Mexico.
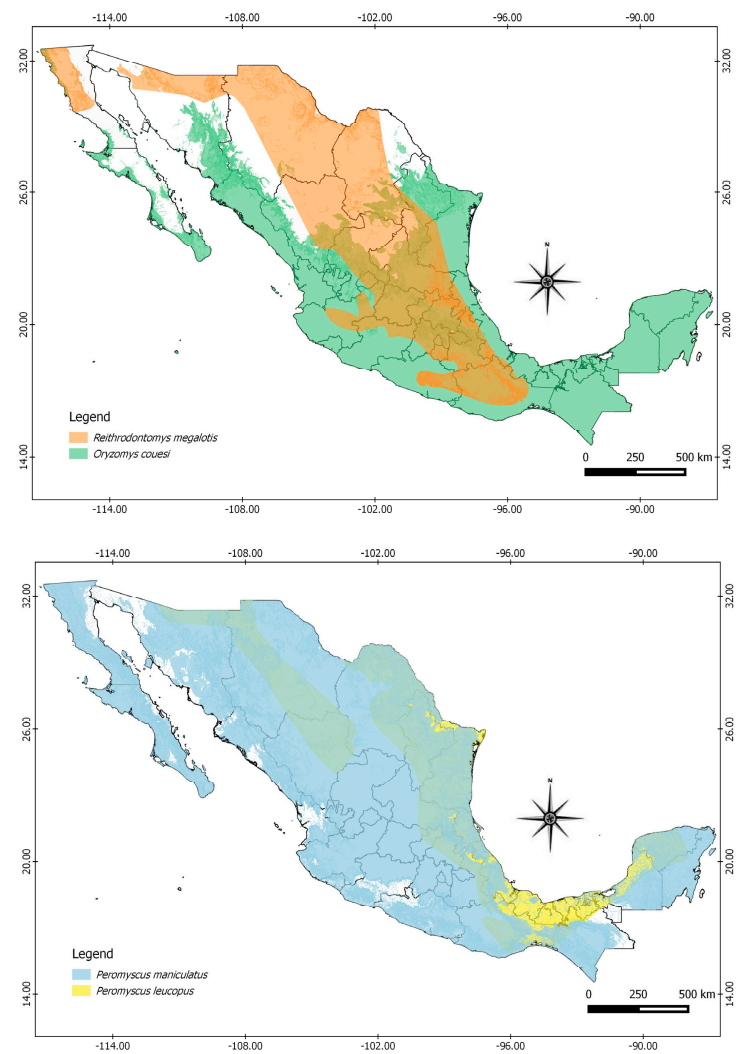

Figure 4. Geographic distribution in Mexico of reservoirs harboring highest Orthohantavirus phylogenetic diversity. 


\section{Discussion}

In Mexico, orthohantaviruses have been non-systematically monitored over the last two decades. Thus far, seven genotypes have been described and 82 host species have been identified. However, Mexico is one of the countries in Latin America with the lowest production of scientific literature about these viruses and their hosts. In the period of 1990-2016, only $2.41 \%$ of publications focused on hantavirus on the continent corresponding to Mexico, whereas Brazil $(38.97 \%)$, Chile $(23.38 \%)$ and Argentina (20.96\%) produced the highest number of studies [26]. This reflects a lack of interest from both scientific and public health perspectives in Mexico, due to the apparent absence of HPS cases. Nevertheless, the similarity of ecosystems, wide distribution of host species, and geographic proximity to sites with HPS cases suggest the opposite.

In Mexico, seroprevalence of Orthohantavirus in rodents is $10.15 \%$, which is higher than southwestern USA $(6.9 \%)$, Colombia $(2.1 \%-4.2 \%)$, and Panama $(2.7 \%)$, but lower compared to Honduras (20.8\%) [27]. In spite of the great variation in the sampling effort for all the states in Mexico, our analytical approach revealed seroprevalence trends. The highest seroprevalences were observed in the states of Hidalgo, Mexico City, and Mexico State. This might be explained by the distributions of reservoir species in the central region of the country, where at least four reservoir species with the highest genetic diversity of orthohantaviruses co-occur. There is regional variation in seroprevalence in the country, with up to $69.22 \%$ seroprevalence in the central region, $49.03 \%$ in the north, $14.88 \%$ in the southeast, and $19.89 \%$ in the west. This is consistent with the findings described by Miholland et al. (2017) who reported high variation in seroprevalence, explained mainly by differences in the species richness, composition, abundance of reservoir species, and habitat heterogeneity among regions [28].

The state of Chihuahua had the highest Orthohantavirus seroprevalence among rodents in the northern region. While there have been no reported cases of HPS in this state, there is evidence of seropositive humans [25]. Interestingly, it represents the area in the USA, along the Mexican border, where 299 cases of HPS were reported between 1993 and 2017 [3]. In a study carried out in humans, in the Yucatan state, there was a seroprevalence of $0.64 \%$, while in rodents the seroprevalence at the same region was $14.9 \%$ [29]. In addition, there was a seroprevalence in humans between $1.4 \%$ to $1.6 \%$ in the states of Colima, Hidalgo, Guanajuato, Mexico City, and Chihuahua [25]. Consistently, all of those states have had evidence of seropositive rodents except Guanajuato (Figure 1), as well as molecular evidence of OROV and LSCV genotypes in Colima and Mexico State, respectively.

There are 254 species of rodents distributed among nine families in Mexico [30]. Our findings provide evidence that the orthohantaviruses have been in contact with the most abundant and widely distributed families in the country-Muridae, Cricetidae, Heteromydae and Sciuridae-with high seroprevalences. Six genera that comprise rodent species recognized as orthohantaviruses reservoirs in America are present in Mexico: Peromyscus, Reithrodontomys, Sigmodon, Oryzomys, Oligoryzomys and Microtus. Among these genera, only Microtus did not show seropositive individuals in Mexico. The species of the genus Peromyscus are the most represented among the samples, and harbor the highest seroprevalence among the species of cricetids in Mexico. The species of the genus Peromyscus are considered the main reservoirs of hantavirus in North America, along with the genera Reithrodontomys and Sigmodon, while the genera Oligoryzomys and Oryzomys are potential hantavirus reservoirs in Central and South America.

Six species of the family Heteromyidae have been reported with seropositive individuals in Mexico, particularly the genus Dipodomys and the species Liomys irruratus, which is a generalist species. Seropositivity among heteromyds is often discarded and considered an accidental [31] result. However, the heteromyds seem to be directly related to the prevalence and maintenance of orthhantavirus in rodent communities, even though their role as reservoirs is unknown [28].

This study identified seropositive individuals of the family Muridae (Rattus rattus and Mus musculus) in Hidalgo, Veracruz and Yucatán. These species are widely distributed in the country and are considered among the most damaging invasive species for ecosystems [32]. Although these findings could be the result of cross-reaction with other orthohantaviruses, systematic surveillance 
in these synantropic species should be implemented. In Chile, both serological and molecular evidence of the Andes Virus have been found in the species Rattus novergicus and Rattus rattus [33,34]. Recently, the first known transmission of the Seoul virus (SEOV) from rats (Rattus novergicus) to humans was reported in the United States and Canada [2]. These findings demonstrate the importance of murid rodents in the transmission and maintenance of viruses among rodents in urban and suburban areas.

Two zoonotic orthhantaviruses have been identified in rodents in Mexico distributed among different states in the country in which no HPS or seropositive humans have been reported (Figure 1, Table 2). The viruses MTNV, HUIV and CARV, considered endemic to Mexico, are phylogenetically closely related to ELMC and LSCV [35], while the OROV is closely related to Bayou virus (BAYV) and Catacamas virus (CATV), but is suggested to be a unique genotype [36]. The 16 orthhantaviruses potentially present in Mexico could be circulating among populations of rodents, as well as soricomorphs. These mammals, in which these hantaviruses have been reported, are distributed in Mexico [11,12,37].

Our finding of high phylogenetic diversity of hantaviruses may be explained by the wide distribution of rodent species, potentially as enzootic reservoirs of Orthohantavirus, in Mexico This could also be explained by the biogeographic convergence that makes Mexico a region with high biodiversity, including high pathogen diversity. Another explanation is that habitat loss and fragmentation of native ecosystems is associated with increases in the abundance of Orthohantavirus reservoirs, and decreases in the species richness of non-host small mammal species [38]. Further research on the diversity of pathogens is important in disease ecology because it allows recognizing ecological associations and evolutionary trends between pathogens and hosts.

Further topics that should be considered for future research include the identification of host switching events and the role of species co-occurrence in infection dynamics. The transmission of orthohantaviruses between species is recognized to favor diversification of these viruses [39]. In Mexico, orthohantaviruses are circulating in different families, genus and species of rodents, and this maybe the result of host switching events [10]. Similarly, studies describing species co-occurrence data have identified novel competent reservoirs in different systems [40,41]. This approach may help to identify potential Orthohantavirus reservoirs in Mexico and recognized areas of high public risk for HPS cases. While substantial knowledge has been accumulated on hantavirus in Mexico, the establishment of disease surveillance programs and the ability to identify cases of hantavirus continue to be strong challenges in the country. This may be possible with the multidisciplinary and inter-institutional participation of the different groups involved in the scientific and public health sectors.

\section{Conclusions}

Hantavirus pulmonary syndrome is a neglected disease in Mexico. Therefore, it is important to strengthen and improve diagnostic strategies in first contact healthcare and in the reference laboratories of the health system for timely detection, establishing appropriate therapies and finally, to know the epidemiological situation of the disease in Mexico. The investigation of the wide diversity of hosts and the enzootic cycles of Orthohantavirus is key in the surveillance of this pathogen.

Supplementary Materials: The following are available online at http://www.mdpi.com/1999-4915/11/7/642/s1, Table S1: Data analyzed by report, Table S2: Seroprevalence by State, Table S3: Seroprevalence by species.

Author Contributions: Conceptualization: A.L.V.-G. and G.S.; methodology: A.L.V.-G., G.S. and G.E.G.-P.; investigation: A.L.V.-G.; data curation: A.L.V.-G.; formal analysis: A.L.V.-G., A.M.L.-P., G.E.G.-P. and O.R.C.; original draft preparation: A.L.V.-G. and G.S.; review and editing: A.L.V.-G., A.M.L.-P., G.E.G.-P., O.R.C., R.E.S.-S. and G.S.; funding acquisition: A.L.V.-G., A.M.L.-P. and G.S.

Funding: Funding for the study was provided by CONACyT with the project no. 2016-01-1851 and by PAPIIT with the project no. IN225219.

Acknowledgments: We thank to Naturalia Comité para la Conservación de Especies Silvestres A. C.; Rafael Ávila-Flores and Wendy S. Sánchez-Gómez for the contribution of new data and samples for the analysis of hantavirus. We thank Audrey Arnal for her review and helpful suggestions for manuscript. A.L. Vigueras-Galván was supported by a CONACyT PhD scholarship. 
Conflicts of Interest: The authors declare that the research was conducted in the absence of any commercial or financial relationships that could be construed as a potential conflict of interest.

\section{References}

1. Watson, D.C.; Sargianou, M.; Papa, A.; Chra, P.; Starakis, I.; Panos, G. Epidemiology of Hantavirus Infections in Humans: A Comprehensive, Global Overview. Crit. Rev. Microbiol. 2014, 40, 261-272. [CrossRef] [PubMed]

2. Kerins, J.L.; Koske, S.E.; Kazmierczak, J.; Austin, C.; Gowdy, K.; Dibernardo, A.; Achenbach, J.; Baber, J.; Balsamo, G.; Behravesh, C.B.; et al. Outbreak of Seoul Virus Among Rats and Rat Owners-United States and Canada, 2017. MMWR Morb. Mortal. Wkly. Rep. 2018, 67, 131-134. [CrossRef] [PubMed]

3. Centers for Disease Control and Prevention. Annual U.S. Hantavirus Disease and HPS Case Fatality, 1993-2016. Available online: https://www.cdc.gov/hantavirus/surveillance/annual-cases.html (accessed on 22 May 2018).

4. Reported Cases of Hantavirus Disease. Hantavirus, DHCPP, CDC. Available online: https://www.cdc.gov/ hantavirus/surveillance/index.html (accessed on 12 May 2019).

5. Ministerio de Salud de Panama. Normativa de Vigilancia Epidemiológica de Hantavirus En Panamá; Instituto Conmemorativo Gorgas de Estudios de la Salud: Calle 36 Este, Panamá, 2016.

6. WHO. Hantavirus disease-Republic of Panama. Available online: http://www.who.int/csr/don/04-January2019-hantavirus-panama/en/ (accessed on 12 May 2019).

7. De Oliveira, R.C.; Júnior, J.B.; Pereira, L.S.; Meneguete, P.S.; Teixeira, B.R.; Guterres, A.; Bonvicino, C.R.; Dias, C.M.G.; de Jesus Oliveira Júnior, R.; Fernandes, J.; et al. A Fatal Hantavirus Pulmonary Syndrome Misdiagnosed as Dengue: An Investigation into the First Reported Case in Rio de Janeiro State, Brazil. Am. J. Trop. Med. Hyg. 2017, 97, 125-129. [CrossRef] [PubMed]

8. Holmes, E.C.; Zhang, Y.-Z. The Evolution and Emergence of Hantaviruses. Curr. Opin. Virol. 2015, 10, $27-33$. [CrossRef] [PubMed]

9. Mills, J.N.; Amman, B.R.; Glass, G.E. Ecology of Hantaviruses and Their Hosts in North America. Vector Borne Zoonotic Dis. 2010, 10, 563-574. [CrossRef] [PubMed]

10. Guo, W.P.; Lin, X.D.; Wang, W.; Tian, J.H.; Cong, M.L.; Zhang, H.L.; Wang, M.R.; Zhou, R.H.; Wang, J.B.; Li, M.H.; et al. Phylogeny and Origins of Hantaviruses Harbored by Bats, Insectivores, and Rodents. PLoS Pathog. 2013, 9, e1003159. [CrossRef]

11. De Araujo, J.; Thomazelli, L.M.; Henriques, D.A.; Lautenschalager, D.; Ometto, T.; Dutra, L.M.; Aires, C.C.; Favorito, S.; Durigon, E.L. Detection of Hantavirus in Bats from Remaining Rain Forest in São Paulo, Brazil. BMC Res. Notes 2012, 5, 690. [CrossRef] [PubMed]

12. Kang, H.J.; Bennett, S.N.; Dizney, L.; Sumibcay, L.; Arai, S.; Ruedas, L.A.; Song, J.-W.; Yanagihara, R. Host Switch during Evolution of a Genetically Distinct Hantavirus in the American Shrew Mole (Neurotrichus Gibbsii). Virology 2009, 388, 8-14. [CrossRef]

13. Hjelle, B.; Torres-Pérez, F. Hantaviruses in the Americas and Their Role as Emerging Pathogens. Viruses 2010, 2, 2559-2586. [CrossRef]

14. Arroyo-Cabrales, J.Y.; Ceballos, G. Lista Actualizada de Los Mamíferos de México 2012. Rev. Mex. Mastozool. 2012, 2, 27-80.

15. Liliana, S.-R.; Simbion T., A.C.; Pachuca de Soto, Hidalgo; Vigueras-Galván Ana L., FMVZ-UNAM, Ciudad de Mexico, Mexico. Rodent blood samples from Hidalgo. Unpublished work. 2009.

16. Rafael, A.-F.; Wendy S., S.-G.; Universidad Juárez Autónoma de Tabasco, Villahermosa, Tabasco, Mexico. Rodent blood samples from Mexico City. Unpublished work. 2015.

17. Gerardo, C.; Naturalia Comité para la Conservación de Especies Sivestres A.C.; Hermosillo, Sonora, Mexico; Vigueras-Galvan Ana L. and López-Pérez Andrés M., FMVZ-UNAM, Ciudad de Mexico, Mexico. Rodent blood samples from Sonora. Unpublished work. 2014.

18. Arriero, E.; Møller, A.P. Host Ecology and Life-History Traits Associated with Blood Parasite Species Richness in Birds. J. Evol. Biol. 2008, 21, 1504-1513. [CrossRef] [PubMed]

19. Tolsá, M.J.; García-Peña, G.E.; Rico-Chávez, O.; Roche, B.; Suzán, G. Macroecology of Birds Potentially Susceptible to West Nile Virus. Proc. R. Soc. B 2018, 285, 20182178. [CrossRef] [PubMed]

20. Faith, D.P. Conservation Evaluation and Phylogenetic Diversity. Biol. Conserv. 1992, 61, 1-10. [CrossRef] 
21. Ceballos, G.; Blanco, S.; González, C.; Martínez, E. Oryzomys couesi (Rata Arrocera). Distribución Potencial, Escala: 1:1000000. In Proyecto DS006: Modelado de La Distribución de Las Especies de Mamíferos de México Para Un Análisis GAP; Con Un Tamaño de Píxel: 0.01 Grados Decimales; El Proyecto Fue Financiado Por La Comisión Nacional Para El Conocimiento y Uso de La Biodi; Instituto de Biología, Universidad Nacional Autónoma de México: Mexico City, México, 2010.

22. Ceballos, G.; Blanco, S.; González, C.; Martínez, E. Peromyscus leucopus (Ratón). Distribución Potencial, Escala: 1:1000000. In Proyecto DS006: Modelado de La Distribución de Las Especies de Mamíferos de México Para Un Análisis GAP; Con Un Tamaño de Píxel: 0.01 Grados Decimales; El Proyecto Fue Financiado Por La Comisión Nacional Para El Conocimiento y Uso de La Biodi; Instituto de Biología, Universidad Nacional Autónoma de México: Mexico City, México, 2010.

23. Ceballos, G.; Blanco, S.; González, C.; Martínez, E. Peromyscus maniculatus (Ratón). Distribución Potencial, Escala: 1:1000000. In Proyecto DS006: Modelado de La Distribución de Las Especies de Mamíferos de México Para Un Análisis GAP; Con Un Tamaño de Píxel: 0.01 Grados Decimales; El Proyecto Fue Financiado Por La Comisión Nacional Para El Conocimiento y Uso de La Biodi; Instituto de Biología, Universidad Nacional Autónoma de México: Mexico City, México, 2010.

24. Ceballos, G.; Blanco, S.; González, C.; Martínez, E. Reithrodontomys megalotis (Ratón). Distribución Potencial, Escala: 1:1000000. In Proyecto DS006: Modelado de La Distribución de Las Especies de Mamiferos de México Para Un Análisis GAP; Con Un Tamaño de Píxel: 0.01 Grados Decimales; El Proyecto Fue Financiado Por La Comisión Nacional Para El Conocimiento y Uso de La Biodi; Instituto de Biología, Universidad Nacional Autónoma de México: Mexico City, México, 2010.

25. Flores-León, R.; Morales-Jímenez, R. Situación de Los Hantavirus En México. Enf. Infect. Microbiol. 2001, 21, 575.

26. Ortiz-Martínez, Y. Estudio de La Producción Científica Sobre Hantavirus En Latinoamérica y El Caribe. Med. Clínica 2017, 148, 575-576. [CrossRef]

27. Montoya-Ruiz, C.; Diaz, F.; Rodas, J. Recent Evidence of Hantavirus Circulation in the American Tropic. Viruses 2014, 6, 1274-1293. [CrossRef] [PubMed]

28. Milholland, M.T.; Castro-Arellano, I.; Arellano, E.; Nava-García, E.; Rangel-Altamirano, G.; Gonzalez-Cozatl, F.X.; Suzán, G.; Schountz, T.; González-Padrón, S.; Vigueras, A.; et al. Species Identity Supersedes the Dilution Effect Concerning Hantavirus Prevalence at Sites across Texas and México. ILAR J. 2017, 58, 401-412. [CrossRef]

29. Vado-Solís, I.; Pérez-Osorio, C.; Lara-Lara, J.; Ruiz-Piña, H.A.; Cárdenas-Marrufo, M.; Milazzo, M.L.; Fulhorst, C.F.; Zavala-Velázquez, J. Evidencia Serológica de Infección Por Hantavirus En Población Humana Del Estado de Yucatán, México. Rev. Biomed. 2003, 14, 221-225. [CrossRef]

30. Sánchez-Cordero, V.; Botello, F.; Flores-Martínez, J.J.; Gómez-Rodríguez, R.A.; Guevara, L.; Gutiérrez-Granados, G.; Rodríguez-Moreno, Á. Biodiversidad de Chordata (Mammalia) En México. Rev. Mex. Biodivers. 2014, 85, 496-504. [CrossRef]

31. Arellano, E.; Castro-Arellano, I.; Suzán, G.; González-Cózatl, F.X.; Jiménez, R.M. Antibody Seroprevalence to Hantaviruses in Rodents from Reserva De La Biosfera Sierra De Huautla, Morelos. West. N. Am. Nat. 2012, 72, 105-109. [CrossRef]

32. Aguirre Muñoz, A.; Mendoza Alfaro, R.; Arredondo Ponce Bernal, H.; Arriaga Cabrera, L.; Campos González, E.; Contreras-Balderas, S.; Gutiérrez, M.E.; Espinosa García, F.J.; Fernández Salas, I.; Galaviz Silva, L.; et al. Especies Exóticas Invasoras: Impactos Sobre Las Poblaciones de Flora y Fauna, Los Procesos Ecológicos y La Economía. In Capital Natural de México, Volume II: Estado de Conservación y Tendencias de Cambio; Comisión Nacional para el Conocimiento y Uso de la Biodiversidad: Mexico City, México, 2009; Volume 2, pp. 277-318.

33. Fernandez, J.; Villagra, E.; Yung, V.; Tognarelli, J.; Araya, P.; Mora, J.; Cattan, P.E.; Ramirez, E. Identification of Andes Hantavirus in Rattus Norvegicus. Arch. Med. Vet. 2008, 40, 295-298. [CrossRef]

34. Lobos, G.; Ferres, M.; Palma, R.E. Presencia de los géneros invasores Mus y Rattus en áreas naturales de Chile: Un riesgo ambiental y epidemiológico. Rev. Chil. Hist. Nat. 2005, 78, 113-124. [CrossRef]

35. Kariwa, H.; Yoshida, H.; Sánchez-Hernández, C.; Romero-Almaraz, M.D.L.; Almazán-Catalán, J.A.; Ramos, C.; Miyashita, D.; Seto, T.; Takano, A.; Totani, M.; et al. Genetic Diversity of Hantaviruses in Mexico: Identification of Three Novel Hantaviruses from Neotominae Rodents. Virus Res. 2012, 163, 486-494. [CrossRef] [PubMed] 
36. Chu, Y.-K.; Owen, R.D.; Sánchez-Hernández, C.; Romero-Almaraz, M.D.L.; Jonsson, C.B. Genetic Characterization and Phylogeny of a Hantavirus from Western Mexico. Virus Res. 2008, 131, 180-188. [CrossRef] [PubMed]

37. Rico-Chávez, O.; Ojeda-Flores, R.; Sotomayor-Bonilla, J.; Zambrana-Torrelio, C.; Loza-Rubio, E.; Aguirre, A.A.; Suzan, G. Viral Diversity of Bat Communities in Human-Dominated Landscapes in Mexico. Vet. México OA 2015, 2, 1-23. [CrossRef]

38. Rubio, A.V.; Ávila-Flores, R.; Suzán, G. Responses of Small Mammals to Habitat Fragmentation: Epidemiological Considerations for Rodent-Borne Hantaviruses in the Americas. EcoHealth 2014, 11, 526-533. [CrossRef] [PubMed]

39. Lin, X.-D.; Wang, W.; Guo, W.-P.; Zhang, X.-H.; Xing, J.-G.; Chen, S.-Z.; Li, M.-H.; Chen, Y.; Xu, J.; Plyusnin, A.; et al. Cross-Species Transmission in the Speciation of the Currently Known Murinae-Associated Hantaviruses. J. Virol. 2012, 86, 11171-11182. [CrossRef]

40. Stephens, C.R.; Heau, J.G.; González, C.; Ibarra-Cerdeña, C.N.; Sánchez-Cordero, V.; González-Salazar, C. Using Biotic Interaction Networks for Prediction in Biodiversity and Emerging Diseases. PLoS ONE 2009, 4, e5725. [CrossRef]

41. Stephens, C.R.; González-Salazar, C.; Sánchez-Cordero, V.; Becker, I.; Rebollar-Tellez, E.; Rodríguez-Moreno, Á.; Berzunza-Cruz, M.; Domingo Balcells, C.; Gutiérrez-Granados, G.; Hidalgo-Mihart, M.; et al. Can You Judge a Disease Host by the Company It Keeps? Predicting Disease Hosts and Their Relative Importance: A Case Study for Leishmaniasis. PLoS Negl. Trop. Dis. 2016, 10, e0005004. [CrossRef]

(C) 2019 by the authors. Licensee MDPI, Basel, Switzerland. This article is an open access article distributed under the terms and conditions of the Creative Commons Attribution (CC BY) license (http://creativecommons.org/licenses/by/4.0/). 